
\title{
ZS Research Square \\ Fingolimod alters intrathecal B cell maturation in multiple sclerosis patients
}

Markus C. Kowarik

Eberhard Karls Universitat Tubingen

David Astling

University of Colorado Denver - Anschutz Medical Campus

Gildas Lepennetier

Klinikum rechts der Isar der Technischen Universitat Munchen

Alanna Ritchie

University of Colorado Denver - Anschutz Medical Campus

Bernhard Hemmer

Klinikum rechts der Isar der Technischen Universitat Munchen

Gregory P. Owens

University of Colorado Denver - Anschutz Medical Campus

Jeffrey L. Bennett ( $\sim$ jeffrey.bennett@cuanschutz.edu )

https://orcid.org/0000-0002-3346-1394

\section{Research}

Keywords: natalizumab, fingolimod, cerebrospinal fluid, B cell migration, B cell maturation, mass sequencing

Posted Date: April 20th, 2020

DOI: https://doi.org/10.21203/rs.3.rs-23388/v1

License: (c) (i) This work is licensed under a Creative Commons Attribution 4.0 International License. Read Full License 


\section{Abstract}

Background: B cells are postulated to play multiple roles in the pathogenesis of multiple sclerosis (MS) including pathogenic antibody production, antigen-presentation and pro-inflammatory cytokine secretion. Natalizumab and fingolimod are effective MS therapies that disrupt lymphocyte migration but exert differential effects on B cell maturation and trafficking. Herein, we investigated their effects on peripheral blood and cerebrospinal fluid (CSF) B cell repertoires.

Methods: Paired CSF and peripheral blood (PB) lymphocytes were collected from MS patients at baseline and after 6 months of treatment with fingolimod $(n=4)$ or natalizumab $(n=4)$. B cell subsets including naïve, CD27+ memory, CD27-IgD- double-negative B cells and plasmablasts were collected by FACS and their respective heavychain variable region $(\mathrm{VH})$ repertoires assessed by next generation deep sequencing (Illumina MiSeq).

Results: Treatment with fingolimod lead to a distinct contraction of the PB B cell pool whereas natalizumab resulted in an expansion of circulating PB B cells. In contrast, CSF B cell numbers remained stable under treatment with fingolimod but decreased following natalizumab therapy. Clonal overlap between CSF and peripheral blood $B$ cells was reduced following natalizumab treatment (-24\% reduction of clonal groups) but remained stable with fingolimod therapy. Lineage analyses of CSF B cell repertoires at baseline and following therapy revealed large, clonally expanded B cell clusters in natalizumab-treated MS patients but no intrathecal clonal expansion following fingolimod therapy.

Conclusions: Our findings suggest that natalizumab treatment diminishes the exchange of peripheral and intrathecal B cells but does not impact intrathecal clonal expansion. In contrast, fingolimod treatment fails to alter B cell exchange across the blood-brain-barrier but affects intrathecal clonal expansion. Sphingosine-1 phosphate receptor inhibition may impact MS disease progression by inhibiting intrathecal germinal center activity.

\section{Background}

B cells play an important role in the pathophysiology of multiple sclerosis (MS). B cells are detected in MS lesions and cerebrospinal fluid (CSF), and the persistence of intrathecal oligoclonal immunoglobulin G (IgG) bands is a fundamental hallmark of disease and associated with worsening disability $[5,16]$. Phase 3 clinical trials have demonstrated that B cell-depleting therapies are effective in reducing clinical and MRI activity in relapsing and progressive forms of disease $[9,10,24]$.

Oral fingolimod and natalizumab are MS therapeutics that interfere with lymphocyte migration and exert distinct effects on B cell trafficking $[11,27]$. Fingolimod is a structural analogue to sphingosine and acts as a superagonist for the sphingosine-1-phosphate receptor 1 (S1P1) on lymphocytes [22] thus inhibiting the egress of lymphocytes from secondary lymphoid tissues. Fingolimod treatment produces a significant peripheral lymphopenia with decreased B cells [23]; the CSF B cell fraction, however, remains elevated [14]. Natalizumab, a monoclonal antibody against a4-integrin, reduces the ability of activated $\mathrm{T}$ cells to migrate through the bloodbrain barrier, producing significantly reduced B cell numbers in the CSF. Following natalizumab treatment, peripheral blood $B$ cells are increased due to the release of memory $B$ cells that are normally attached to the marginal sinus of the spleen via alpha 4 integrins $[14,20,31]$. 
The purpose of this study was to compare and contrast CNS B cell trafficking and distribution in natalizumaband fingolimod-treated MS patients using massively parallel DNA sequencing of immunoglobulin heavy chain (VH) repertoires. In total, 8 patients receiving either natalizumab or fingolimod were studied at baseline (TO) and following 6 months (T6) of treatment. At each time point, CSF and peripheral blood B cells were sorted into naïve, memory, double-negative and plasmablast populations and $\mathrm{VH}$ repertoires assessed by next generation mass sequencing. Comparison of Ig repertoires between the peripheral blood and CSF compartments at baseline and over time indicated that natalizumab treatment diminished but did not completely block the migration of B cells into the CSF. In contrast, fingolimod significantly reduced peripheral blood B cell numbers and CSF B cell clonal expansion without diminishing B cell migratory potential.

\section{Methods}

\section{Standard protocol approvals, registrations and patients}

Patients with relapsing remitting multiple sclerosis were recruited into the study at the University of Colorado, School of Medicine from 2013-2014 following Institutional Review Board-approved informed consent. Study inclusion criteria were the following: 1 ) diagnosis of clinically definite MS according to International (McDonald 2011) or Poser criteria; 2) age between 18-65 years of age; 3 ) the ability to give informed consent; and 4) normal vital signs. Exclusion criteria included 1) CNS disease in addition to MS; 2) primary progressive or secondary progressive forms of MS; 3 ) bacterial or viral infection within the last 30 days; 4) prior immunomodulatory or immunosuppressant therapy with natalizumab, oral fingolimod, azathioprine, methotrexate, cyclophosphamide, mitoxantrone, rituximab, daclizumab, mycophenolate mofetil, laquinimod, oral fumarate, or total body irradiation; and 5) treatment within the last 30 days with corticosteroids, beta-interferon, glatiramer acetate, plasma exchange, or intravenous immunoglobulin. The planned analysis was for 8 patients: 4 natalizumab and 4 oral fingolimod. Nine patients were recruited; a single patient withdrew from participation after initial lumbar puncture. Treatment with oral fingolimod or natalizumab was initiated at the discretion of the patient's treating physician. The study duration was 6 months with peripheral blood and CSF obtained at study entry and exit. Additional fluorescence-activated cell sorting (FACS) analyses were performed on peripheral blood B cells from untreated, natalizumab-treated, and fingolimod-treated MS patients (15 per cohort) at the Technical University of Munich following Institutional Review Board-approved informed consent. Clinical and demographic data for each patient cohort is presented in supplementary materials (Suppl. Table 1).

\section{Specimen handling and routine CSF testing}

CSF (5-20 ml) and blood (25 ml collected in CPT tubes; BD Vacutainer) were collected according to standard procedures at the same study visit from patients at baseline and after 6 months of treatment with fingolimod or natalizumab using standard dosing. Routine CSF and serum analyses (Table 1) showed no significant differences between treatment groups. 
Table 1

Routine MS patient CSF and serum analysis at baseline and 6-months post treatment with either fingolimod or natalizumab (Ig mass sequencing cohort).

\begin{tabular}{|c|c|c|c|c|c|c|c|c|}
\hline & \multicolumn{2}{|c|}{ Subject 2} & \multicolumn{2}{|c|}{ Subject 3} & \multicolumn{2}{|c|}{ Subject 4} & \multicolumn{2}{|c|}{ Subject 8} \\
\hline $\begin{array}{l}\text { Age (yr), } \\
\text { Gender }\end{array}$ & \multicolumn{2}{|l|}{$52, F$} & \multicolumn{2}{|l|}{$43, F$} & \multicolumn{2}{|l|}{$57, F$} & \multicolumn{2}{|l|}{$53, F$} \\
\hline $\begin{array}{l}\text { Disease } \\
\text { Duration } \\
\text { (mo) }\end{array}$ & \multicolumn{2}{|l|}{53} & \multicolumn{2}{|l|}{95} & \multicolumn{2}{|l|}{98} & \multicolumn{2}{|l|}{168} \\
\hline $\begin{array}{l}\text { Time } \\
\text { since } \\
\text { relapse } \\
\text { (mo) }\end{array}$ & \multicolumn{2}{|l|}{14} & \multicolumn{2}{|l|}{24} & \multicolumn{2}{|l|}{54} & \multicolumn{2}{|l|}{6} \\
\hline $\begin{array}{l}\text { Prior MS } \\
\text { therapies }\end{array}$ & \multicolumn{2}{|l|}{ None } & \multicolumn{2}{|c|}{ INF, GLAT, NAT } & \multicolumn{2}{|l|}{ GLAT } & \multicolumn{2}{|c|}{ INF, GLAT, NAT, DMF } \\
\hline $\begin{array}{l}\text { Time } \\
\text { since last } \\
\text { Tx (mo, } \\
\text { Tx) }\end{array}$ & \multicolumn{2}{|l|}{ N/A } & \multicolumn{2}{|c|}{14, NAT } & \multicolumn{2}{|c|}{ 1, GLAT } & \multicolumn{2}{|c|}{ 11, DMF } \\
\hline \multirow[t]{2}{*}{ EDSS } & \multicolumn{2}{|l|}{1} & \multicolumn{2}{|l|}{1.5} & \multicolumn{2}{|l|}{1.5} & \multicolumn{2}{|l|}{3} \\
\hline & $\begin{array}{l}\text { Pre- } \\
\text { Rx }\end{array}$ & Fingolimod & $\begin{array}{l}\text { Pre- } \\
\text { Rx }\end{array}$ & Fingolimod & $\begin{array}{l}\text { Pre- } \\
\text { Rx }\end{array}$ & Fingolimod & $\begin{array}{l}\text { Pre- } \\
\text { Rx }\end{array}$ & Fingolimod \\
\hline $\begin{array}{l}\text { CSF } \\
\text { Glucose }\end{array}$ & 59 & 57 & 56 & 54 & ND & 64 & 56 & 63 \\
\hline $\begin{array}{l}\text { CSF } \\
\text { Protein }\end{array}$ & 36 & 29 & 54 & 50 & 24 & 24 & 21 & 27 \\
\hline WBC & 0 & 4 & 3 & 0 & 0 & 0 & 0 & 0 \\
\hline $\begin{array}{l}\text { Ser lgG } \\
(\mathrm{mg} / \mathrm{dl})\end{array}$ & 749 & 667 & 568 & 753 & 952 & 946 & 637 & 652 \\
\hline $\begin{array}{l}\text { Ser Alb } \\
(\mathrm{mg} / \mathrm{dl})\end{array}$ & 3970 & 4480 & 4340 & 4100 & 4220 & 4340 & 4770 & 4450 \\
\hline $\begin{array}{l}\text { CSF Alb } \\
(\mathrm{mg} / \mathrm{dl})\end{array}$ & 22 & 22 & 34 & 31 & 14 & 17 & 15 & 17 \\
\hline $\begin{array}{l}\text { Albumin } \\
\text { Index }\end{array}$ & 5,5 & 4,9 & 7,8 & 7,6 & 3,3 & 3,9 & 3,1 & 3,8 \\
\hline $\begin{array}{l}\text { lgG CSF } \\
(\mathrm{mg} / \mathrm{dl})\end{array}$ & 3 & 2,6 & 5,3 & 5,1 & 1,7 & 1,7 & 1,2 & 1,3 \\
\hline IgG Index & 0,72 & 0,79 & 1,19 & 0,9 & 0,54 & 0,46 & 0,6 & 0,52 \\
\hline
\end{tabular}

There were no significant differences between treatment groups in baseline serum and CSF values (MannWhitney U test). Abbreviations: $\mathrm{WBC}=$ white blood count, Ser $=$ Serum, $\mathrm{CSF}=$ cerebrospinal fluid, $\mathrm{OCB}=$ oligoclonal bands, Pre-Rx = baseline, $\mathrm{MS}=$ multiple sclerosis, $\mathrm{yr}=$ years, $\mathrm{mo}=$ months, $\mathrm{Tx}=$ treatment, GLAT = glatiramer, INF = interferon, NAT = natalizumab, DMF = dimethyl fumarate. 


\begin{tabular}{|c|c|c|c|c|c|c|c|c|}
\hline \multirow[b]{2}{*}{$\begin{array}{l}\operatorname{lgG} / \text { Alb } \\
\text { Ratio }\end{array}$} & \multicolumn{2}{|c|}{ Subject 2} & \multicolumn{2}{|c|}{ Subject 3} & \multicolumn{2}{|c|}{ Subject 4} & \multicolumn{2}{|c|}{ Subject 8} \\
\hline & 0,14 & 0,12 & 0,16 & 0,16 & 0,12 & 0,1 & 0,08 & 0,08 \\
\hline $\begin{array}{l}\text { OCB \# of } \\
\text { bands }\end{array}$ & 13 & 10 & 15 & 12 & 0 & 0 & 1 & 1 \\
\hline \multirow{2}{*}{$\begin{array}{l}\text { IgG } \\
\text { Synthesis }\end{array}$} & 3 & 3,4 & 14,4 & 10 & 0 & 0 & 0 & 0 \\
\hline & \multicolumn{2}{|c|}{ Subject 1} & \multicolumn{2}{|c|}{ Subject 5} & \multicolumn{2}{|c|}{ Subject 6} & \multicolumn{2}{|c|}{ Subject 7} \\
\hline $\begin{array}{l}\text { Age (yr), } \\
\text { Gender }\end{array}$ & \multicolumn{2}{|l|}{$20, \mathrm{~F}$} & \multicolumn{2}{|l|}{$35, \mathrm{M}$} & \multicolumn{2}{|l|}{$22, F$} & \multicolumn{2}{|l|}{$39, F$} \\
\hline $\begin{array}{l}\text { Disease } \\
\text { Duration } \\
\text { (mo) }\end{array}$ & \multicolumn{2}{|l|}{2} & \multicolumn{2}{|l|}{4} & \multicolumn{2}{|l|}{115} & \multicolumn{2}{|l|}{42} \\
\hline $\begin{array}{l}\text { Time } \\
\text { since } \\
\text { relapse } \\
\text { (mo) }\end{array}$ & \multicolumn{2}{|l|}{2} & \multicolumn{2}{|l|}{4} & \multicolumn{2}{|l|}{12} & \multicolumn{2}{|l|}{2} \\
\hline $\begin{array}{l}\text { Prior MS } \\
\text { therapies }\end{array}$ & \multicolumn{2}{|l|}{ None } & \multicolumn{2}{|l|}{ None } & \multicolumn{2}{|l|}{ GLAT } & \multicolumn{2}{|c|}{ GLAT, INF, DMF } \\
\hline $\begin{array}{l}\text { Time } \\
\text { since last } \\
\text { Tx (mo, } \\
\text { Tx) }\end{array}$ & \multicolumn{2}{|l|}{$\mathrm{N} / \mathrm{A}$} & \multicolumn{2}{|l|}{$\mathrm{N} / \mathrm{A}$} & \multicolumn{2}{|c|}{ 1, GLAT } & \multicolumn{2}{|c|}{ 5, DMF } \\
\hline \multirow[t]{2}{*}{ EDSS } & \multicolumn{2}{|l|}{2.5} & \multicolumn{2}{|l|}{2.5} & \multicolumn{2}{|l|}{1.5} & \multicolumn{2}{|l|}{2.5} \\
\hline & $\begin{array}{l}\text { Pre- } \\
\text { Rx }\end{array}$ & Natalizumab & $\begin{array}{l}\text { Pre- } \\
\mathrm{Rx}\end{array}$ & Natalizumab & $\begin{array}{l}\text { Pre- } \\
\text { Rx }\end{array}$ & Natalizumab & $\begin{array}{l}\text { Pre- } \\
\text { Rx }\end{array}$ & Natalizumab \\
\hline $\begin{array}{l}\text { CSF } \\
\text { Glucose }\end{array}$ & 54 & 55 & 56 & 55 & 54 & 53 & 52 & 62 \\
\hline $\begin{array}{l}\text { CSF } \\
\text { Protein }\end{array}$ & 32 & 21 & 68 & 50 & 27 & 26 & 29 & 38 \\
\hline WBC & 3 & 0 & 14 & 2 & 11 & 2 & 2 & 2 \\
\hline $\begin{array}{l}\text { Ser IgG } \\
(\mathrm{mg} / \mathrm{dl})\end{array}$ & 935 & 559 & 775 & 946 & 855 & 719 & 1120 & 1120 \\
\hline $\begin{array}{l}\text { Ser Alb } \\
(\mathrm{mg} / \mathrm{dl})\end{array}$ & 4470 & 3130 & 4870 & 4360 & 4580 & 4730 & 3150 & 4010 \\
\hline $\begin{array}{l}\text { CSF Alb } \\
\text { (mg/dl) }\end{array}$ & 18 & 15 & 56 & 35 & 19 & 18 & 17 & 17 \\
\hline $\begin{array}{l}\text { Albumin } \\
\text { Index }\end{array}$ & 4 & 4,8 & 11,5 & 8 & 4,1 & 3,8 & 5,4 & 4,2 \\
\hline $\begin{array}{l}\text { There wer } \\
\text { Whitney U } \\
\text { oligoclona } \\
\text { glatiramer }\end{array}$ & $\begin{array}{l}\text { signi } \\
\text { ). Abl } \\
\text { nds, I }\end{array}$ & $\begin{array}{l}\text { ant difference } \\
\text { viations: WBC } \\
\text { Rx = baseline } \\
\text { eron, NAT = na }\end{array}$ & $\begin{array}{l}\text { vetwee } \\
\text { white } \\
\text { IS =m } \\
\text { lizum }\end{array}$ & $\begin{array}{l}\text { reatment grou } \\
\text { od count, Ser } \\
\text { iple sclerosis, } \\
\text { DMF = dimeth }\end{array}$ & $\begin{array}{l}\text { S in bas } \\
\text { Serum, } \\
=\text { years } \\
\text { fumara }\end{array}$ & $\begin{array}{l}\text { line serum an } \\
\text { SF = cerebrosp } \\
\text { no = months, }\end{array}$ & $\begin{array}{l}\text { CSF val, } \\
\text { nal fluid, } \\
x=\text { treatr }\end{array}$ & $\begin{array}{l}\text { Ies (Mann- } \\
\text { OCB = } \\
\text { nent, GLAT = }\end{array}$ \\
\hline
\end{tabular}




\begin{tabular}{|c|c|c|c|c|c|c|c|c|}
\hline \multirow[b]{2}{*}{$\begin{array}{l}\text { IgG CSF } \\
(\mathrm{mg} / \mathrm{dl})\end{array}$} & \multicolumn{2}{|c|}{ Subject 2} & \multicolumn{2}{|c|}{ Subject 3} & \multicolumn{2}{|c|}{ Subject 4} & \multicolumn{2}{|c|}{ Subject 8} \\
\hline & 3,1 & 1,7 & 9 & 6,9 & 3,2 & 2,4 & 8,7 & 7,6 \\
\hline IgG Index & 0,82 & 0,63 & 1,01 & 1,14 & 0,9 & 0,88 & 1,44 & 1,6 \\
\hline $\begin{array}{l}\text { IgG/Alb } \\
\text { Ratio }\end{array}$ & 0,17 & 0,11 & 0,16 & 0,2 & 0,17 & 0,13 & 0,51 & 0,45 \\
\hline $\begin{array}{l}\text { OCB \# of } \\
\text { bands }\end{array}$ & 6 & 7 & 17 & 13 & 19 & 10 & 17 & 15 \\
\hline $\begin{array}{l}\text { IgG } \\
\text { Synthesis }\end{array}$ & 3,4 & 0,6 & 22,5 & 18,2 & 5 & 2,9 & 25,8 & 26,2 \\
\hline \multicolumn{9}{|c|}{$\begin{array}{l}\text { There were no significant differences between treatment groups in baseline serum and CSF values (Mann- } \\
\text { Whitney U test). Abbreviations: WBC = white blood count, Ser = Serum, CSF = cerebrospinal fluid, OCB = } \\
\text { oligoclonal bands, Pre-Rx = baseline, MS = multiple sclerosis, yr = years, mo = months, Tx = treatment, GLAT = } \\
\text { glatiramer, INF = interferon, NAT = natalizumab, DMF = dimethyl fumarate. }\end{array}$} \\
\hline
\end{tabular}

\section{Cell staining and sorting of CSF and blood B cell populations}

CSF cells and blood mononuclear cells (MNCs) were collected by centrifugation, washed with phosphatebuffered saline (PBS) and suspended in PBS containing $5 \%$ fetal calf serum. Cells were then incubated (40 min) on ice with antibodies to the following cell markers: CD27 PE (Becton Dickinson), CD38 APCCy5.5 (Invitrogen), CD19 PacBlue (AbDserotec), IgD APC (Becton Dickinson), CD14 FITC (AbDserotec), CD56 FITC (Becton Dickinson), CD20 FITC (Biolegend), CD16 FITC (eBioscience), CD3 FITC (Becton Dickinson). After staining, cells were washed and suspended in PBS for FACS. CD1 $19^{+} \mathrm{CD} 20^{+}$and $\mathrm{CD} 19^{+} \mathrm{CD} 20^{\text {low }} \mathrm{B}$ cell subsets (Suppl. Figure 2) were first selected from other cell populations as previously described [15]. Naïve B cells $\left(\mathrm{CD} 19^{+} \mathrm{CD} 20^{+} \operatorname{lgD}{ }^{+} \mathrm{CD} 27^{-}\right)$and memory B cells $\left(\mathrm{CD} 19^{+} \mathrm{CD} 20^{+} \mathrm{CD} 27^{+}\right)$were further separated from the $\mathrm{CD} 19^{+} \mathrm{CD} 20^{+}$population, whereas double negative $\mathrm{B}$ cells $\left(\mathrm{CD} 19^{+} \mathrm{CD} 20^{\text {low }} \mathrm{CD} 27^{-} \mathrm{IgD}{ }^{-} \mathrm{CD} 38^{+}\right)$and plasmablasts $\left(\mathrm{CD} 19^{+} \mathrm{CD} 20^{\text {low }} \mathrm{CD} 27^{+} \mathrm{CD} 38^{\text {high }} \mathrm{IgD}{ }^{-}\right)$were obtained from the $\mathrm{CD} 19^{+} \mathrm{CD} 20^{\text {low }}$ population. The gating strategy (Suppl. Figure 2) and numbers of PB and CSF B cells collected from each population per subject (Suppl. Table 2) are provided in supplementary materials. Additional analytic FACS of peripheral blood (TU Munich cohort) used antibodies against CD38 FITC (Becton Dickinson), IgD PE (Biozol), CD19 ECD (Beckman Coulter), CD138 PeCy5.5 (Beckman Coulter), CD3 PeCy7 (Beckman Coulter), CD45 VM (Becton Dickinson), CD27 APC (Becton Dickinson), and CD20 APC Cy7 (Becton Dickinson).

\section{CSF and Blood VH transcriptome library preparation and deep sequencing}

Total RNA was extracted from peripheral blood and CSF B cell populations using the Qiagen RNeasy Plus Micro Kit per manufacturer's instructions. cDNA was synthesized using the Clontech SMARTer Ultra Low RNA Kit for Illumina sequencing according to the manufacturer's instructions, containing an amplification step during second strand CDNA synthesis. During the double-stranded CDNA synthesis step, conserved constant region primers for IgA, IgG and IgM were added to enrich immunoglobulin transcripts during amplification [15].

Following generation of ds cDNA libraries, a pool of modified, $\mathrm{VH}$-family-specific (VH1-VH5) and isotype-specific ( IgD, IgM, IgG, and IgA) nested $C$ region primers were used to amplify $\mathrm{VH}$-region sequences using polymerase chain reaction (PCR high fidelity, Roche). Separate PCR reactions were performed for each VH-family to avoid 
cross-priming or primer competition. Each nested Ig constant region primer contained a sequence tag ("barcode") to identify the specific patient $B$ cell population of origin and Ig isotype, a random sequence insert (unique molecular identifier; UMI) to identify PCR over-replication [13], and a unique shared primer sequence for subsequent Illumina MiSeq deep sequencing. Forward primers contained a primer sequence for sense strand sequencing. Amplified CDNA from peripheral blood and CSF B cell subsets of each subject and from each time point (before and after treatment) were separately pooled and sequenced in a single run on an Illumina MiSeq Personal Sequence yielding 16 individual VDJ libraries from the 8 MS patients. Our approach allowed to sequence the entire heavy chain variable region with a maximum of $600 \mathrm{bp}$.

\section{Data analysis}

According to their barcodes, Illumina sequencing reads in FASTQ format were pre-sorted into patient-specific B cell populations. Illumina MiSeq high-throughput sequencing reads were quality-controlled, assembled, and filtered using pRESTO [34]. The workflow took advantage of our unique molecular identifiers (UMIs) to eliminate redundant reads from the same PCR priming event.

The complementarity determining region-3 (CDR3) of the $\mathrm{VH}$ gene results from the recombination of the variable, diversity, and joining $[\mathrm{V}(\mathrm{D}) \mathrm{J}]$ germline segments. Functional heavy chain $[\mathrm{V}(\mathrm{D}) \mathrm{J}]$ germline segments were determined using IMGT/HighV-QUEST [1] and assigned into clones based on (1) identical nucleic acid CDR3 sequence length, (2) identical $V$ and $J$ gene segments, and (3) 80\% nucleotide CDR3 sequence identity. From identified clonal groups within the same patient populations, lineage analysis (rooted B cell lineage trees) was performed using IgTree [2] (kindly provided by Prof. Ramit Mehr, Bar-llan University, Tel Aviv) to sort clones based on their mutational distance from germline. Alignments were initiated at nucleotide 75 . The germline used as the root of each clonal tree was determined by automatically searching for the best match of the $\mathrm{V}$ and $\mathrm{J}$ alleles from the IgBlast genes (Blastn v2.2.31), concatenating both alleles into a sequence $(G)$ that was then aligned to each member of the clonal group. Because the $D$ segment is often difficult to determine, we filled in the missing gaps of the CDR3 region in the sequence $(\mathrm{G})$ by Ns in order to avoid hypervariable region bias in IgTree.

Each clonal group tree was then converted to a graphml file using in-house conversion tools and improved via Cytoscape functionalities. The program GNU parallel was used at multiple steps in the assembly of full-length VDJ sequences. Using the output of IgTree, it was also possible to evaluate the relatedness of Ig transcripts over time (T0 vs. T6) and across compartments (peripheral blood vs. CSF).

\section{Protocol for tree sorting and detailed lineage analyses}

The IgTree program produces, in addition to numeric images, ".vsdot" files. Those files contain descriptive information for each individual tree. Using in-house python scripts, we extracted the tree structure and composition. All trees were then automatically sorted step by step as described in Suppl. Table 3 and then manually refined. After the refinement, nodes in the lineage tree were labeled based on the compartment (peripheral blood or CSF) and B cell subtype of the most frequent sequence in that clonal group.

\section{Statistics}

Wilcoxon signed-rank test (one-sided) for paired samples was used to test for significance between different time points within treatment groups. The Mann-Whitney $\mathrm{U}$ test was used to test for significant differences between treatment groups. For comparison of different B cell subsets the non-parametric Kruskal-Wallis test with multiple comparison correction (Dunn's procedure) was applied. 


\section{Results}

\section{Clinical and laboratory data}

Nine patients from the Rocky Mountain Multiple Sclerosis Center at Anschutz Medical Campus were recruited for participation based on inclusion/exclusion criteria and signed informed consent. One patient withdrew after the initial lumbar puncture. MS treatment was pre-determined by the patient's treating physician. Two natalizumab patients and one fingolimod patient were treatment naïve; all initiated therapy within roughly 1 year of their initial presentation. The remaining five patients had received prior MS treatments including beta-interferon, glatiramer acetate, natalizumab, and dimethyl fumarate. Five patients ( 3 fingolimod and 2 natalizumab) switched therapy due to disease activity. Two changed treatments after clinical relapses ( 2 and 6 months, respectively), while the others switched due to new disease activity on MRI. Both relapses occurred while off of therapy. No patients experienced a clinical relapse during the 6-month study period. All standard of care brain MRIs performed 12 months after treatment did not show any new lesion activity (further clinical data Supplemental Table 1). Although 2 patients from the natalizumab treatment group showed a mild CSF pleocytosis at the onset of treatment, there were no significant difference in any baseline CSF parameters between treatment groups (Table 1). There were no significant differences in the changes from baseline in any CSF parameter between treatments (Table 1).

We examined alterations in peripheral blood B cell subsets in an independent cohort (TU-Munich, Suppl. Table 1) of treatment naïve and fingolimod- and natalizumab-treated MS patients. Due to their differing modes of action, distinct treatment-specific changes were noted in peripheral blood B cell subsets (Fig. 1A). Fingolimod treatment caused a significant decrease in the percentage of total peripheral blood $C D 19^{+} B$ cells $(p=0.01)$ predominantly within the naïve (2.6-fold, $p<0.001$ ), plasmablast (3.3-fold, $p<0.01$ ) and memory $B$ cell subsets (13.8-fold, $p<$ $0.01)$; DN B cells were marginally affected. Conversely, natalizumab treatment increased the percentage of total peripheral blood B cells $(p<0.05)$ with significant increases observed in the memory $(2.4$-fold, $p<0.01)$ and DN B cell pools $(1.5$-fold, $p=0.05)$. Similar changes were observed in peripheral $B$ cell subsets in the fingolimod-and natalizumab-treated deep sequencing cohort of 8 patients (Fig. 1B).

Within the CSF, the number of recovered B cells did not change appreciably from baseline following fingolimod therapy (Suppl. Table 2). A modest increase in the fraction of naïve B cells ( $2.2 \mathrm{fold})$ and a decrease in plasmablasts (3.8 fold) were observed (Fig. 1B). Natalizumab treatment however, produced a 2-fold reduction in B cell recovery with memory B cells ( 3.1 fold) and plasmablasts ( 6 fold) most affected.

\section{Ig repertoires generated from blood and CSF B cell subsets}

B cell clonal expansion is observed within the CSF compartment of MS patients. To assess changes in the clonal relationships within and between CSF and blood B cells following therapy, B cell subsets (naïve, memory, doublenegative $B$ cells and plasmablasts) were sorted and functional heavy-chain $(\mathrm{VH})$ repertoires generated using Illumina next generation deep sequencing (Suppl. Table 2) in the 8 MS patients recruited at the University of Colorado. On average, 78586 sequences from blood B cell subsets (range 20329-243433 sequences) and 14130 sequences from CSF B cell subsets (range 241-102028 sequences) were processed through the PRESTO bioinformatics pipeline to obtain representative VH repertoires for each B cell population (Suppl. Table 2). 
At baseline, the distributions of $\mathrm{VH}$ isotypes in peripheral blood $\mathrm{B}$ cell populations were $50 \% \operatorname{lgD}$ and $50 \% \lg \mathrm{M}$ in the naïve B cell population; $50 \% \lg$ M, 30\% IgA and $20 \% \operatorname{lgG}$ in the memory population; and $26 \% \lg \mathrm{M}, 53 \% \lg \mathrm{A}$ and $21 \% \lg$ in the DN population (not shown). Plasmablasts were $30 \% \lg$ M, $40 \% \lg A$ and $30 \% \lg$. In the CSF, at baseline, there was a significantly higher fraction of lgG-expressing B cells in the memory, DN and plasmablast subsets compared to peripheral blood (not shown). There were no significant changes in the distribution of Ig isotypes in the peripheral blood and CSF subsets following treatment with either medication (Suppl. Figure 1A).

Prior to the onset of treatment, the VH germline distribution of peripheral blood B cell subsets approximated germline prevalence; the VH3 family was most frequently utilized, followed by the VH1 and VH4 family gene segments [3] (Suppl. Figure 1B). The baseline VH germline distribution in the CSF, however, showed a significant increase in VH4 family gene segments consistent with independent findings observed at the single-cell level in MS CSF plasmablasts [25]. Increased VH4 germline segment usage was accompanied by a significant decline in VH1 and VH5 family gene segments. Treatments had no discernable effects on VH family distributions in peripheral blood and CSF (Suppl. Figure 1B). In the CSF, there was a significant increase in Ig class-switched B cells relative to peripheral blood that was accompanied by sharp declines in CSF IgM- and IgD-expressing B cells (Suppl. Figure 1A). Consistent with these results, we observed a significantly lower diversity index for CSF B cells when compared to those in the periphery, indicating, that CSF B cells are predominantly composed of antigen experienced, clonally-expanded populations (Suppl. Figure 1C).

\section{Changes in PB and CSF VH repertoires following treatment}

We established representative CSF and PB B cell repertoires at baseline (T0) and after 6 months (T6) of treatment in 3 of 4 fingolimod-and all 4 natalizumab-treated patients. The recovery of peripheral blood $\mathrm{VH}$ sequences represented on average $9.8 \%$ of sorted cells, whereas in CSF, sequence yields were much higher at 75.3\%. The increased sequencing efficiency observed in the CSF B cell population likely reflects the increased prevalence of activated, class-switched memory B cells and plasmablasts containing increased levels of immunoglobulin transcripts.

Within the CSF compartment, approximately $80 \%$ of VH sequences were within clonal populations (Table 2 ). As expected, CSF B cells categorized as naïve B cells had the lowest percentage of clonal sequences whereas fully differentiated plasmablasts contained the most (data not shown). Further comparisons were precluded due to considerable variability in the number and average size of clonal populations among different CSF B cell subsets at T0. Overall, the percentage of total CSF VH sequences in clonal populations remained stable following treatment. In fingolimod-treated patients, an increase in the average number of clonal populations was accompanied by a decrease in average clone size; whereas in natalizumab-treated patients, a decrease in the average number of clonal populations was accompanied by a significant increase in average clonal size (Table 2). 
Table 2

Clonal analyses of Ig repertoires within the peripheral blood and cerebrospinal fluid of treatment cohorts.

\begin{tabular}{|c|c|c|c|c|c|}
\hline & \multicolumn{2}{|c|}{ Fingolimod } & \multicolumn{2}{|c|}{ Natalizumab } & \multirow{2}{*}{$\begin{array}{l}\text { Fingolimod vs. } \\
\text { Natalizumab } \\
\text { T6 }\end{array}$} \\
\hline & TO & T6 & TO & T6 & \\
\hline \multicolumn{6}{|l|}{ CSF Sequences } \\
\hline \multirow[t]{2}{*}{$\begin{array}{l}\% \text { CSF sequences in clones / } \\
\text { SDM }\end{array}$} & $\begin{array}{l}71 \% / \\
\pm 27 \%\end{array}$ & $\begin{array}{l}77 \% / \\
\pm 13 \%\end{array}$ & $\begin{array}{l}89 \% / \\
\pm 3 \%\end{array}$ & $\begin{array}{l}82 \% / \\
\pm 8 \%\end{array}$ & \multirow[t]{2}{*}{$p=N S$} \\
\hline & $p=N S$ & & $p=N S$ & & \\
\hline \multirow[t]{2}{*}{ Average \# of clones / SDM } & $13 / \pm 9$ & $28 / \pm 31$ & $\begin{array}{l}221 / \\
\pm 176\end{array}$ & $18 / \pm 6$ & \multirow[t]{2}{*}{$p=N S$} \\
\hline & \multicolumn{2}{|c|}{ TO vs. T6: $p=N S$} & \multicolumn{2}{|c|}{ T0 vs. T6: $p=0.06$} & \\
\hline \multirow{2}{*}{$\begin{array}{l}\text { Average \# of sequences per } \\
\text { clone / SDM }\end{array}$} & $44 / \pm 38$ & $18 / \pm 9$ & $17 / \pm 5$ & $35 / \pm 9$ & \multirow[t]{2}{*}{$p=N S$} \\
\hline & TO vs. T6 & $=N S$ & TO vs. T & $=0.06$ & \\
\hline \multicolumn{6}{|l|}{ PB Sequences } \\
\hline \multirow[t]{2}{*}{$\begin{array}{l}\% \text { PB sequences in clones / } \\
\text { SDM }\end{array}$} & $\begin{array}{l}46 \% / \\
\pm 9 \%\end{array}$ & $\begin{array}{l}74 \% / \\
\pm 19 \%\end{array}$ & $\begin{array}{l}54 \% / \\
\pm 7 \%\end{array}$ & $\begin{array}{l}38 \% / \\
\pm 4 \%\end{array}$ & \multirow[t]{2}{*}{$p=0.03$} \\
\hline & \multicolumn{2}{|c|}{ TO vs. T6: $p=N S$} & \multicolumn{2}{|c|}{ T0 vs. T6: $p=0.06$} & \\
\hline \multirow[t]{2}{*}{ Average \# of clones / SDM } & $\begin{array}{l}1697 / \\
\pm 683\end{array}$ & $\begin{array}{l}447 / \\
\pm 136\end{array}$ & $\begin{array}{l}3727 / / \\
\pm 2526\end{array}$ & $\begin{array}{l}4122 / \\
\pm 1502\end{array}$ & \multirow[t]{2}{*}{$p=0.03$} \\
\hline & \multicolumn{2}{|c|}{ T0 vs. T6: $p=N S$} & \multicolumn{2}{|c|}{ TO vs. T6: $p=N S$} & \\
\hline \multirow[t]{2}{*}{$\begin{array}{l}\text { Average\# of sequences per } \\
\text { clone / SDM }\end{array}$} & $4 / \pm 1$ & $10 / \pm 4$ & $4 / \pm 1$ & $4 / \pm 0$ & \multirow[t]{2}{*}{$p=0.03$} \\
\hline & \multicolumn{2}{|c|}{ TO vs. T6: $p=N S$} & \multicolumn{2}{|c|}{ TO vs. T6: $p=N S$} & \\
\hline \multicolumn{6}{|c|}{$\begin{array}{l}\mathrm{SDM}=\text { standard deviation of the mean, } \mathrm{CSF}=\text { cerebrospinal fluid, } \mathrm{PB}=\text { peripheral blood, } \mathrm{TO}=\text { baseline, } \mathrm{T} 6=6 \\
\text { months of treatment, } N S=\text { not significant. Wilcoxon signed-rank test (paired samples) was used to test } \\
\text { between different time points, Mann-Whitney U test was used to test between treatment groups. }\end{array}$} \\
\hline
\end{tabular}

Following treatment, there were considerable changes in the composition of peripheral blood VH repertoires (Table 2). At baseline, approximately $50 \%$ of peripheral blood VH sequences were found within clonal groups with an average clone size of 4 sequences. Following fingolimod treatment, the percentage of peripheral blood $\mathrm{VH}$ sequences within clones increased to $74 \%$ with an average clone size of 10 sequences; whereas following natalizumab treatment, the percentage of clonal $\mathrm{VH}$ sequences in the peripheral blood reduced this to $38 \%$ with a stable clone size of 4 sequences. The average clone size in the peripheral blood memory B cell populations increased following fingolimod treatment $(T 0=5, T 6=14$ sequences/clone, $p=N S)$ and decreased $(T 0=4, T 6=3$ sequences/ clone, $p=0.04$ ) following natalizumab therapy (data not shown).

4. Clonal relationships between peripheral blood (PB) and CSF repertoires at baseline and 6 months following treatment 
The prevalence of CSF VH sequences identified in paired peripheral blood repertoires at the onset of therapy was $34.8 \%$ in fingolimod- and $30.5 \%$ in natalizumab-treated patients (range: $6.5 \%-49.8 \%$ ) (Table 3 ). After six months, neither treatment significantly altered this overlap. The percentage of blood $\mathrm{VH}$ sequences identified in the CSF was considerably lower, consistent with the increased diversity of the peripheral blood repertoire (Table 3). Comparing between therapies, there was an increase in the fraction of overlapping PB and CSF VH sequences in fingolimod-treated relative to natalizumab-treated patients (Table 3).

Table 3

Overlap of VH repertoires between and within the peripheral blood and cerebrospinal fluid in treatment cohorts.

\begin{tabular}{|c|c|c|c|c|c|}
\hline & \multicolumn{2}{|c|}{ Fingolimod } & \multicolumn{2}{|c|}{ Natalizumab } & \multirow{2}{*}{$\begin{array}{l}\text { Fingolimod vs. } \\
\text { Natalizumab } \\
\text { T6 }\end{array}$} \\
\hline & TO & T6 & TO & T6 & \\
\hline \multicolumn{6}{|l|}{ Between PB and CSF } \\
\hline \multirow[t]{2}{*}{$\begin{array}{l}\text { \% CSF sequences in clones } \\
\text { with PB / SDM }\end{array}$} & $\begin{array}{l}34.8 \% / \\
\pm 9.5 \%\end{array}$ & $\begin{array}{l}29.2 \% / \\
\pm 24.6 \%\end{array}$ & $\begin{array}{l}30.5 \% / \\
\pm 19.1 \%\end{array}$ & $\begin{array}{l}22.5 \% / \\
\pm 13.0 \%\end{array}$ & \multirow[t]{2}{*}{$p=N S$} \\
\hline & \multicolumn{2}{|c|}{ TO vs. T6: $p=N S$} & \multicolumn{2}{|c|}{ T0 vs. T6: $p=N S$} & \\
\hline \multirow[t]{2}{*}{$\begin{array}{l}\% \text { PB sequences in clones with } \\
\text { CSF / SDM }\end{array}$} & $\begin{array}{l}2.2 \% / \\
\pm 1.5 \%\end{array}$ & $\begin{array}{l}7.1 \% / \\
\pm 3.1 \%\end{array}$ & $\begin{array}{l}5.1 \% / \\
\pm 2.9 \%\end{array}$ & $\begin{array}{l}1.5 \% / \\
\pm 0.7 \%\end{array}$ & \multirow[t]{2}{*}{$p=0.03$} \\
\hline & \multicolumn{2}{|c|}{ TO vs. T6: $p=N S$} & \multicolumn{2}{|c|}{ TO vs. T6: $p=N S$} & \\
\hline \multicolumn{6}{|l|}{ Within CSF or PB } \\
\hline $\begin{array}{l}\text { \% CSF sequences in clones } \\
\text { over time / SDM }\end{array}$ & \multicolumn{2}{|c|}{$0.3 \% / \pm 0.4 \%$} & \multicolumn{2}{|c|}{$6.2 \% / \pm 4.8 \%$} & $p=0.04$ \\
\hline $\begin{array}{l}\text { \% PB sequences in clones over } \\
\text { time / SDM }\end{array}$ & \multicolumn{2}{|c|}{$0.7 \% / \pm 0.8 \%$} & \multicolumn{2}{|c|}{$5.5 \% / \pm 2.6 \%$} & $p=0.03$ \\
\hline
\end{tabular}

SDM = standard deviation of the mean, CSF = cerebrospinal fluid, PB = peripheral blood, $\mathrm{T0}=$ baseline, $\mathrm{T} 6=6$ months of treatment, $N S=$ not significant. Wilcoxon signed-rank test (paired samples) was used to test between different time points, Mann-Whitney $U$ test was used to test between treatment groups.

\section{Supplementary information}

Supplemental Fig. 1: VH isotype distribution, VH family distribution and diversity

Supplemental Fig. 2: gating strategy

Supplemental Table 1: Clinical and demographic data of MS patients

Supplemental Table 2: Cell counts and number of VH sequences

Supplemental Table 3: Description of sorting guidelines for the development of clonal maturation trees.

Supplemental Table 4: Lineage analysis of clonal groups between the CSF and PB.

Supplemental Table 5: Lineage analysis of clonal groups between baseline (T0) and after 6 months of treatment (T6)

We next examined the longitudinal effects of treatment on clonal dynamics within the CSF and PB compartments (Table 3). The percentage of baseline CSF sequences identified following 6 months of treatment 
was limited following either treatment but was lower in fingolimod-treated subjects (0.3\% vs. $6.2 \%)$. Even within the highly clonal CSF plasmablast repertoires, the persistence of baseline clones was reduced to $0.1 \%$ overlap in the fingolimod-treated patients versus $8.3 \%$ overlap in natalizumab-treated patients (data not shown). A similar significant treatment-specific effect was noted in the persistence of PB clones. Again, fingolimod-treated subjects displayed a significant longitudinal reduction in overlapping sequences relative to natalizumab-treated subjects (0.7\% vs. 5.5\%) (Table 3).

\section{Lineage analysis of overlapping $\mathrm{VH}$ sequences}

We aligned clonally related blood and CSF VH sequences to their most homologous germline sequence, developed hierarchical maturation diagrams (clonal groups) using IgTree, and found 659 of 1019 clonal groups suitable for a qualitative analysis of clonal relationships amongst B cell subsets and compartments. The succession of B cell subtypes and their patterns of somatic hypermutations were then used to predict the most likely direction of maturation (in or out of the CSF). Overall, 388 clonal comparisons were established between CSF and PB at each time point (Fig. 2) and 271 clonal groups within the CSF between baseline (T0) and 6 months of treatment (T6) (Fig. 3). We observed directional B cell trafficking with a blood B cell followed by a CSF B cell in $90 \%$ of the trees (Fig. 2, clones A-C, E) whereas $10 \%$ of comparisons indicated a likely CSF precursor (Fig. 2, clone D). We further quantified the size of clonal groups by counting the number of contributing sequences within each compartment and B cell subset to determine the likely site of clonal expansion at T0 and T6 (Fig. 4, Suppl. Table 4).

We first separately analyzed bi-compartmental clonal groups (CG) connecting PB and CSF sequences at baseline or after 6 months of treatment (Fig. 4A-C, Suppl. Table 4). Although fingolimod treatment did not affect the average number of clones shared between CSF and peripheral blood (T0 = 14 and T6 $=15)$ there was a clear shift towards PB B cells as the major contributor (T0: $60 \%$ of sequences; T6: > 95\% of sequences), which was accompanied by a parallel loss in the contribution of expanded CSF B cells (T0: $n=106$ to T6: $n=18,-85 \%$ ), particularly CSF plasmablasts, to common lineages (Fig. 4B). Together the data indicate that PB B cell trafficking into the CNS was not outwardly altered by fingolimod therapy, but rather clonal expansion of CSF B cells diminished. Indeed, there were significantly fewer number of average CSF sequences at T6 following fingolimod treatment $(n=18)$ when compared to natalizumab $(n=133, p=0.03)$; the difference at T0 between groups was not significant (Fig. 4A). Following natalizumab treatment, there was a modest decline in the average number of clones shared between CSF and circulating B cells (T0: $n=46 ;$ T6: $n=35,-24 \%$ ), but with no apparent shift in the compartmental contributions of CSF (T0: $n=183$ to T6: $n=133,-27 \%$ ) or PB sequences (T0: $n=535$ to T6: $n=$ $401,-25 \%)$. The major site of clonal expansion (PB, CSF or equally in both compartments) and changes following treatment are summarized in Fig. 4C. Following fingolimod treatment, there was an increase in PB expanded clones (from $74 \%$ at T0 to $91 \%$ at T6), a decreased contribution of CSF expanded clones (14\% at T0 to $5 \%$ at T6), and an overall reduction in clones equally abundant in both compartments (14\% at T0 to $5 \%$ at T6). In natalizumab-treated patients, the distribution of major clonal B cell populations was rather static and consisted mostly of PB memory, DN B cells and plasmablasts (Fig. 4B and 4C). CSF plasmablasts were still the major CSF contributor to clonality ( 15\%).

Further evidence for impaired B cell expansion within the CSF during fingolimod treatment is indicated from the longitudinal analysis of shared CSF and B cell maturation trees (Fig. 4D-F, Suppl. Table 5). Following treatment, none of the CSF-expanded clones at T0 were identified in the CSF at T6, and only a single clone arising from the CSF DN B cell population was identified in the peripheral blood PB DN and memory B cell subsets. Thus 
treatment with fingolimod appeared to halt expansion of existing clonal B cell populations within the CSF; some of the remaining clones overlapping with clonal populations evident in the peripheral blood at T0 (Fig. 4E, 4F).

In contrast, on average 4 (total $=11$ ) clonal groups connected the CSF compartment between T0 and T6 following natalizumab treatment with more than $50 \%$ of shared T0 clonal sequences (T0: $330, T 6: 168)$ still present. Furthermore, an average of 10 clonal groups (total $n=30$ ) were found connecting CSF at T0 and the PB at T6 (Fig. 4D) with only a limited number of average clonal sequences in PB at T6 $(n=18)$. CSF plasmblasts, memory, and DN B cells, which were the major contributors to clonality at T0 in the natalizumab-treated cohort, changed only marginally at T6. An equal distribution of clonal expansion was observed between the different time points. These results point towards continued B cell maturation within the CSF compartment in natalizumab-treated patients over time.

In addition, we analyzed clonal groups connecting PB at T0 and PB and CSF at T6 (Fig. 4G, H and I, Suppl. Table 5). The average number of clonal groups between both time points was significantly lower following fingolimod treatment when compared to natalizumab (fingolimod $n=7$ vs. natalizumab $n=41, p=0.03$ ). Only a very limited number of clones (fingolimod $n=2$; natalizumab $n=4$ ) connected peripheral blood at T0 with CSF at T6 under both therapies. The average number of contributing sequences between both time points remained relatively stable (Fig. $4 \mathrm{G}$ ). The distribution of clonal populations amongst PB plasmablasts and memory $B$ cells remained stable between T0 and T6 following fingolimod treatment with only a few clones noted in the CSF DN and memory populations at T6 (Fig. 4H). In natalizumab-treated patients, mainly PB plasmablasts (20\%), PB memory B cells (60\%) and PB DN B cells (14\%) connected with PB plasmablasts (31\%), PB memory B cells (46\%), PB DN B cells (8\%) and CSF plasmablasts (11\%). The major site of clonal expansion (Fig. 4I) in fingolimod-treated patients was found in the PB at 6 months but was equally distributed between the PB and CSF in natalizumab-treated patients (Fig. 4F).

\section{Discussion}

B cells are likely to play multiple roles in the MS pathogenesis $[9,24]$. In this study we investigated the effects of fingolimod and natalizumab on the migration and clonal expansion of B cells before and after 6 months of treatment in a total of eight MS patients by assessing lg VH repertoires in the peripheral blood and CSF using next generation sequencing. Our findings suggest that natalizumab treatment might diminish but not completely block the migration of B cells into the CSF; whereas fingolimod significantly reduces peripheral blood B cell numbers (Fig. 1) and clonal populations (Table 2) without affecting the exchange of B cells across the blood brain barrier (Fig. 4). In addition, fingolimod appears to reduce B cell maturation and expansion of migratory $B$ cells within the CSF compartment resulting in depletion of pre-existing clonal populations.

While our analysis was limited by patient numbers and the limited number of recoverable CSF B cells in treated patients, our study provides detailed information on the differential treatment effects of two highly-effective MS therapies on B cell repertoires in the PB and CSF. In agreement with prior publications [14, 19], CSF B cell numbers recovered from fingolimod patients remained generally stable but declined in natalizumab treated patients. As anticipated, fingolimod reduced the number of circulating $B$ cells in the PB while natalizumab resulted in an increase in PB B cells $[14,31,32]$. The distinctive contraction and expansion of the circulating PB B cell population by fingolimod and natalizumab may have influenced the ability to detect related sequences in the blood and CSF compartments. 
Our results at baseline (T0) are comparable to recent analyses of CSF and peripheral blood $\mathrm{VH}$ repertoires in untreated MS patients $[26,30,35]$. In these studies, clonal relationships were observed between CSF B cells and peripheral (class switched) memory, double negative B cells and plasmablasts [26], and the patterns of mutations in $\mathrm{VH}$ sequences in bi-compartmental clones are consistent with migration of B cell populations across the blood-brain-barrier accompanied by expansion within the CNS. In our analysis, variable degrees of overlapping sequences were identified based on the comparator population employed. Before treatment, the overlap between the PB and CSF in our 8 patients was 3.8\% using the blood repertoires as a comparator or $34 \%$ when using CSF repertoires as the comparator. In previous studies, the average percentage of overlap was lower, with only $6.3 \%$ (range $0.6 \%-23.5 \%$ ) of the CSF B cells detected in the peripheral blood repertoire [35]. The distinctions are likely due to the different processing of Ig repertoires, the definition of clones, distinct patient populations, and different depths of mass sequencing. Similar to prior bicompartmental MS B cell repertoire analyses [26, 30,35], lineage analyses of clonal groups between the CSF and blood compartment in our patients suggested a bidirectional exchange of B cells across the blood-brain-barrier. In contrast to previous studies [26], we also found a limited overlap of PB naïve B cells to the CSF compartment $(<10 \%)$ which could be explained by a greater depth of sequencing in our analyses; memory, DN B cells and plasmablasts from the peripheral blood all contributed approximately $30 \%$ to clonal groups emanating from PB.

After 6 months of therapy with either fingolimod or natalizumab, we observed distinct effects on the quantitative overlap of sequences and B cell lineage trees (clonal groups) between the PB and CSF compartments although results have to be interpreted with care due to the limited number of patients. Following fingolimod treatment, the percentage overlap of PB derived sequences to the CSF repertoire increased while the number of linked CSF and PB clonal groups remained stable (Fig. 4A). In contrast, natalizumab treatment reduced both the percentage overlap of PB derived sequences to the CSF repertoire and the number of linked clonal groups (Fig. 4A). This reduction following natalizumab treatment is consistent with its known effects on restricting activated immune cell trafficking to the CNS. The high frequency of clonal groups shared between PB and CSF under fingolimod treatment suggests that despite the limited number of PB B cells CSF migration remains unaffected. This is consistent with previous observations demonstrating a relatively high fraction of $B$ cells in the CSF of patients receiving fingolimod therapy $[14,19]$. In the current study, the increased overlap between the peripheral blood and CSF B cells in fingolimod-treated patients, may be magnified by the significant contraction of the circulating PB B cell population.

In addition, our results suggest that fingolimod may inhibit the lifespan of B cells or germinal center activity within the CNS. In our longitudinal analyses of CSF and blood repertoires pre- and post-treatment, we noted a lower amount of overlapping sequences and clonal populations in fingolimod-treated patients when compared to natalizumab-treated or untreated MS patients. Furthermore, detailed lineage analyses revealed that clonal expansion was significantly reduced compared to that observed following natalizumab treatment (Fig. 3). The limited detection of clonal groups connecting the peripheral blood compartment between T0 and T6 in fingolimod-treated patients may have been due to sequestration of PB B cells in peripheral lymphoid tissue. However, no clonal groups persisted amongst pre- and post-treatment CSF B cells under fingolimod treatment at all. In addition, after 6 months of fingolimod treatment, the number of clonal groups connecting the peripheral blood and CSF remained stable but showed a smaller contribution from CSF B cells and a larger contribution from clonally-expanded peripheral blood B cells. This indicates that B cells still enter the CSF under fingolimod treatment but might not undergo further somatic hypermutation and clonal expansion within the CSF

Page $14 / 25$ 
compartment. Looking at the composition of B cell subsets in clonal groups between the PB and CSF compartment at T0 and T6, the percentage of CSF plasmablasts was reduced under fingolimod treatment, indicating that the occurrence of newly emerging antibody producing plasmablasts might be inhibited by the drug. Although circulating memory B cells are decreased in the peripheral blood of fingolimod-treated MS patients, memory B cells appear to maintain an intensive exchange across the blood-brain-barrier.

Our results on persisting clonal groups in the CSF of MS patients show some similarities to a recently published paper examining treated and untreated MS patients [6]. In general, the number of persisting clonal populations were lower than in our study (range 1-9) and were preferentially found in patients who experienced relapse during the observational period (9-22 months). Amongst those patients receiving natalizumab or fingolimod ( $n$ $=2$ for each therapy), persisting clonal populations were noted in only one individual for each treatment. Both of these patients, however, showed clinical and MRI activity over an observation period of more than 12 months, making it difficult to compare with our patients who were clinically and radiologically stable over 6 months. Additional variability likely results from the limited number of patients in both studies and limited number of CSF B cells to be sampled in natalizumab- and fingolimod-treated patients.

The combined effects of fingolimod on the PB and CSF B cell repertoires suggests that intrathecal fingolimod may reduce CNS germinal center activity. Although a role of alpha4 integrins in peripheral lymphoid tissue compartmentalization has been established in animal models [20], a similar effect of natalizumab on germinal center reactions in the CSF is unlikely. The transit of natalizumab across the blood-brain-barrier as an antibody is limited and CSF concentration levels of natalizumab are 350 times less than in serum [8]. In contrast, natalizumab is more likely to affect $B$ cell trafficking across the blood-brain-barrier in agreement with recent studies in EAE models [18]. Phosphorylated FTY720 (fingolimod) readily crosses the blood-brain-barrier and is capable of interacting with CNS-resident cell populations $[17,28]$. Previous work in the mouse experimental autoimmune encephalomyelitis (EAE) model has shown that fingolimod becomes ineffective in mice selectively deficient for sphingosine 1-phosphate 1 receptors on astrocytes [4]. In addition, fingolimod ameliorates chronic progressive experimental autoimmune encephalitis mediated by astrocytes, microglia and pro-inflammatory monocytes [28], and mice treated with fingolimod demonstrate a significant reduction of germinal center activity in peripheral lymphoid tissues [7]. To the best of our knowledge, there are no directly comparable data regarding the effects of fingolimod on CNS germinal center activity in humans.

Our analysis of the overlap between the CSF and peripheral blood B cells in MS patients under fingolimod and natalizumab treatment has several limitations. First, we evaluated only four patients in each treatment group limiting the power of our analyses and leaving some results at a descriptive level. Despite this limitation, we were still able to detect significant differences between treatment groups. Second, we observed a more intense overlap between the PB and CSF compartment at baseline in MS patients receiving natalizumab. While these differences were not significant, physician biases and disease activity may have biased patient selection into the treatment groups thereby influencing the results. Indeed, natalizumab treated patients showed a shorted disease duration and lower age; however, EDSS values were only slightly higher in the natalizumab cohort (Suppl. Table 1). Nevertheless, we were able to generate representative repertoires in both treatment groups, and our subsequent analyses, normalized by the total number of obtained sequences, were consistent when comparing the total number of overlapping sequences with the detailed analyses of clonal groups. Third, while lineage analysis provides a unique tool to study B cell trafficking in MS, mass sequencing of B cell Ig repertoires only allows a snapshot of the $B$ cell repertoire at a certain time and does not fully represent the dynamic relationship amongst

Page $15 / 25$ 
transiting B cells. This may be further skewed by the process of repertoire reconstruction. Although we optimized our protocol to obtain a maximum recovery of Ig sequences from B cells, efficient amplification of $\mathrm{VH}$ sequences from memory and naïve B cells is challenging. In addition, despite safeguards such as high fidelity PCR and UMIs, sequencing errors and over-amplification of transcripts may result in artificial or over-represented B cell clusters or clones. In fact, we observed roughly $50 \%$ of naïve B cells in clones containing a small number of mutations from germline (3.5 sequences / clone). This could represent sequencing error or activation within the naïve $B$ cell pool [33]. We have worked to minimize any such bias by validating each individual Ig lineage tree according to B cell subsets, distance to germline, and time point of analysis.

\section{Conclusion}

In summary, our results confirm that natalizumab inhibits but does not completely block the migration of B cells across the blood-brain-barrier. Natalizumab, however, does not impair B cell germinal center activity within the CNS. While the exchange of PB B cells across the blood-brain-barrier does not seem to be inhibited following fingolimod treatment, B cell numbers are significantly reduced in the peripheral blood. More importantly, B cells seem to be inhibited in their ability to undergo further maturation within the CNS. Especially in the context of progressive MS, in which ongoing germinal center activity within the CNS may be compartmentalized [29], CNS penetration of sphingosine-1-phosphate (S1P) inhibitors may offer a unique avenue to modulate the intrathecal $B$ cell response. Although fingolimod treatment did not reach primary end-points in the INFORMS trial in primary progressive MS, MRI parameters of disease activity showed a significant reduction in the number of T2 lesions [21]. Recently, siponimod, a more selective S1P receptor functional antagonist demonstrated benefit in the treatment of SPMS [12] and was recently approved by the FDA. Thus, S1P receptor inhibitors may have significant effects on trapped CNS inflammation in progressive MS patients. Further studies of different S1P receptors and their effects on B cell maturation within the CSF / CNS in a larger patient collective will be necessary to fully understand the effects of this class of compounds on the B cell compartment.

\section{List Of Abbreviations}

PB: peripheral blood; CSF: cerebrospinal fluid; VH: heavy-chain variable region; MS: multiple sclerosis; DN: double negative; Ig: immunoglobulin; S1P: sphingosine-1-phosphate; T0: baseline; T6: 6 months of treatment; CNS: central nervous system; FACS: fluorescence-activated cell sorting; MNCs: mononuclear cells; PBS: phosphatebuffered saline; UMI: unique molecular identifier; CG: clonal group; SPMS: secondary progressive multiple sclerosis; FDA: U.S. Food and Drug Administration

\section{Declarations}

\section{Ethics approval and consent to participate}

All patients consented to the scientific use of their biosamples. The ethics committee of the University of Colorado, School of Medicine and Technische Universität München approved the scientific use of biosamples.

\section{Consent for publication}

Not applicable. 


\section{Availability of data and materials}

The datasets used and/or analyzed during the current study are available from the first author on reasonable request.

\section{Competing interests}

MCK: receives financial support (travel compensation, IIT, scientific advisory boards) from Merck, SanofiGenzyme, Biogen, Celgene and Novartis, all not related to this work.

DA: has no competing interests.

GL: has no competing interests.

AR: has no competing interests.

$\mathrm{BH}$ : has served on scientific advisory boards for Novartis; he has served as DMSC member for AllergyCare and TG therapeutics; he or his institution have received speaker honoraria from Desitin; holds part of two patents; one for the detection of antibodies against KIR4.1 in a subpopulation of MS patients and one for genetic determinants of neutralizing antibodies to interferon. All conflicts are not relevant to the topic of the study.

GPO: has no competing interests.

JLB: serves as a consultant for Clene Nanomedicine, Viela Bio, Chugai Pharmaceutical, EMD Serono, Equillium, Alexion, Roche, Genentech, and Novartis; and receives research support from Mallinckrodt.

\section{Funding}

This work was funded by the NIH (R01EY022936 to JLB); National MS Society and an independent investigator grant from Novartis Pharmaceutical (JLB). Bernhard Hemmer received support from the Deutsche Forschungsgemeinschaft (DFG, German Research Foundation) under Germany's Excellence Strategy within the framework of the Munich Cluster for Systems Neurology (EXC 2145 SyNergy - ID 390857198) and the EU project MultipleMS. M. C. Kowarik was supported by the Deutsche Forschungsgesellschaft (DFG, Ko 4367/1-1) and SyNergy.

\section{Author contributions:}

Kowarik M.C.: Study design, experimental methods, data analysis and manuscript preparation. Astling D: Established bioinformatics pipeline to analyze MiSeq data, performed sample analysis. Lepennetier G.: Performed data analysis with special regard to lineage trees. Ritchie A.: experimental methods. Hemmer B.: Study design, manuscript preparation. Owens G.P: Data analysis, sample preparation and bioinformatics analysis, manuscript preparation. Bennett J.L.: Sample acquisition, study design, data analysis, manuscript preparation.

\section{Acknowledgments:}

None. 


\section{References}

1. Alamyar E, Duroux P, Lefranc MP, Giudicelli V. IMGT((R)) tools for the nucleotide analysis of immunoglobulin (IG) and T cell receptor (TR) V-(D)-J repertoires, polymorphisms, and IG mutations: IMGT/V-QUEST and IMGT/HighV-QUEST for NGS. Methods Mol Biol. 2012;882:569

2. Barak M, Zuckerman NS, Edelman H, Unger R, Mehr R. IgTree: creating Immunoglobulin variable region gene lineage trees. J Immunol Methods. 2008;338:67-74

3. Brezinschek, HP, Foster SJ, Brezinschek RI, Dorner T, Domiati-Saad R, and Lipsky PE. Analysis of the human VH gene repertoire. J Clin Invest. 1998;99:2488-2501

4. Choi JW, Gardell SE, Herr DR, Rivera R, Lee CW, Noguchi K, , et al. FTY720 (fingolimod) efficacy in an animal model of multiple sclerosis requires astrocyte sphingosine 1-phosphate receptor 1 (S1P1) modulation. Proc Natl Acad Sci U S A. 2011;108:751-756

5. Gasperi C, Salmen A, Antony G, Bayas A, Heesen C, Kümpfel T, et al. Association of Intrathecal Immunoglobulin G Synthesis With Disability Worsening in Multiple Sclerosis. JAMA Neurol. 2019;76:841-849

6. Greenfield AL, Dandekar R, Ramesh A, Eggers EL, Wu H, Laurent S, et al. Longitudinally persistent cerebrospinal fluid B cells can resist treatment in multiple sclerosis. JCI Insight. 2019; doi:

10.1172/jci.insight.126599

7. Han S, Zhang X, Wang G, Guan H, Garcia G, Li P, et al. FTY720 suppresses humoral immunity by inhibiting germinal center reaction. Blood. 2004;104:4129-33

8. Harrer A, Pilz G, Wipfler P, Oppermann K, Sellner J, Hitzl W, et al. High interindividual variability in the CD4/CD8 T cell ratio and natalizumab concentration levels in the cerebrospinal fluid of patients with multiple sclerosis. Clin Exp Immunol. 2015;180:383-92

9. Hauser SL, Bar-Or A, Comi G, Giovannoni G, Hartung HP, Hemmer B, et al. Ocrelizumab versus Interferon Beta1a in Relapsing Multiple Sclerosis. N Engl J Med. 2017;376:221-234

10. Kappos L, Li D, Calabresi PA, O'Connor P, Bar-Or A, Barkhof F, et al. Ocrelizumab in relapsing-remitting multiple sclerosis: a phase 2, randomised, placebo-controlled, multicentre trial. Lancet. 2011;378:1779-1787

11. Kappos L, Radue EW, O'Connor P, Polman C, Hohlfeld R, Calabresi P, et al. A placebo-controlled trial of oral fingolimod in relapsing multiple sclerosis. N Engl J Med. 2010;362:387-401.

12. Kappos L, Bar-Or A, Cree BAC, Fox RJ, Giovannoni G, Gold R, et al. Siponimod versus placebo in secondary progressive multiple sclerosis (EXPAND): a double-blind, randomised, phase 3 study. 2018;391(10127):12631273.

13. Kivioja T, Vähärautio A, Karlsson K, Bonke M, Enge M, Linnarsson S, et al. Counting absolute numbers of molecules using unique molecular identifiers. Nature methods. 2012;9:72-74

14. Kowarik MC, Pellkofer HL, Cepok S, Korn T, Kümpfel T, Buck D, et al. Differential effects of fingolimod (FTY720) on immune cells in the CSF and blood of patients with MS. Neurology. 2011;76:1214-1221

15. Kowarik MC, Astling D, Gasperi C, Wemlinger S, Schumann H, Dzieciatkowska M, et al. CNS Aquaporin-4specific B cells connect with multiple B-cell compartments in neuromyelitis optica spectrum disorder. Ann Clin Transl Neurol. 2017;4:369-380

16. Krumbholz M, Meinl E. B cells in MS and NMO: pathogenesis and therapy. Semin Immunopathol. 2014;36:339-350 
17. Lee CW, Choi JW, Chun J. Neurological S1P signaling as an emerging mechanism of action of oral FTY720 (fingolimod) in multiple sclerosis. Arch Pharm Res. 2010;33:1567-74.

18. Lehmann-Horn K, Sagan SA, Bernard CC, Sobel RA, Zamvil SS. B-cell very late antigen-4 deficiency reduces leukocyte recruitment and susceptibility to central nervous system autoimmunity. Ann Neurol. 2015;77:9028.

19. Lohmann L, Janoschka C, Schulte-Mecklenbeck A, Klinsing S, Kirstein L, Hanning U, et al. Immune Cell Profiling During Switching from Natalizumab to Fingolimod Reveals Differential Effects on Systemic Immune-Regulatory Networks and on Trafficking of Non-T Cell Populations into the Cerebrospinal FluidResults from the ToFingo Successor Study. Front Immunol. 2018;9:1560

20. Lu TT, Cyster JG. Integrin-mediated long-term B cell retention in the splenic marginal zone. Science. 2002;297:409-12

21. Lublin F, Miller DH, Freedman MS, Cree BA, Wolinsky JS, Weiner H, et al. Oral fingolimod in primary progressive multiple sclerosis (INFORMS): a phase 3, randomised, double-blind, placebo-controlled trial. 2016;387:1075-84

22. Mandala S, Hajdu R, Bergstrom J, Quackenbush E, Xie J, Milligan J, etal. Alteration of lymphocyte trafficking by sphingosine-1-phosphate receptor agonists. Science. 2002;296:346-349

23. Matloubian M, Lo CG, Cinamon G, Lesneski MJ, Xu Y, Brinkmann V, et al. Lymphocyte egress from thymus and peripheral lymphoid organs is dependent on S1P receptor 1. Nature. 2004;427:355-360

24. Montalban X, Hauser SL, Kappos L, Arnold DL, Bar-Or A, Comi G, et al. Ocrelizumab versus Placebo in Primary Progressive Multiple Sclerosis. N Engl J Med. 2017;376:209-220

25. Owens GP, Winges KM, Ritchie AM, Edwards S, Burgoon MP, Lehnhoff L, et al. VH4 gene segments dominate the intrathecal humoral immune response in multiple sclerosis. J Immunol. 2007;179:6343-51

26. Palanichamy A, Apeltsin L, Kuo TC, Sirota M, Wang S, Pitts SJ, et al. Immunoglobulin class-switched B cells form an active immune axis between CNS and periphery in multiple sclerosis. Sci Transl Med. 2014;6:248ra106

27. Polman $\mathrm{CH}$, O'Connor PW, Havrdova E, Hutchinson M, Kappos L, Miller DH, et al. A randomized, placebocontrolled trial of natalizumab for relapsing multiple sclerosis. N Engl J Med 2006;354:899-910

28. Serafini B, Rosicarelli B, Magliozzi R, Stigliano E, Aloisi F. Detection of ectopic B-cell follicles with germinal centers in the meninges of patients with secondary progressive multiple sclerosis. Brain Pathol. 2004;14:164-74

29. Stern JN, Yaari G, Vander Heiden JA, Church G, Donahue WF, Hintzen RQ, et al. B cells populating the multiple sclerosis brain mature in the draining cervical lymph nodes. Sci Transl Med. 2014;6:248ra107

30. Rothhammer V, Kenison JE, Tjon E, Takenaka MC, de Lima KA, Borucki DM, et al. Sphingosine 1-phosphate receptor modulation suppresses pathogenic astrocyte activation and chronic progressive CNS inflammation. Proc Natl Acad Sci U S A. 2017.pii:201615413

31. Stüve O, Marra CM, Jerome KR, Cook L, Cravens PD, Cepok S, et al. Immune surveillance in multiple sclerosis patients treated with natalizumab. Ann Neurol. 2006;59:743-747

32. Traub JW, Pellkofer HL, Grondey K, Seeger I, Rowold C, Brück W, et al. Natalizumab promotes activation and pro-inflammatory differentiation of peripheral $\mathrm{B}$ cells in multiple sclerosis patients. J Neuroinflammation.

2019;16:228 
33. Tipton CM, Fucile CF, Darce J, Chida A, Ichikawa T, Gregoretti I, et al. Diversity, cellular origin and autoreactivity of antibody-secreting cell population expansions in acute systemic lupus erythematosus. Nat Immunol. 2015;16:755-65

34. Vander Heiden JA, Yaari G, Uduman M, Stern JN, O'Connor KC, Hafler DA, et al. pRESTO: a toolkit for processing high-throughput sequencing raw reads of lymphocyte receptor repertoires. Bioinformatics. 2014;30:1930-1932

35. von Büdingen HC, Kuo TC, Sirota M, van Belle CJ, Apeltsin L, Glanville J, et al. B cell exchange across the blood-brain barrier in multiple sclerosis. J Clin Invest. 2012;122:4533-43

\section{Supplemental Files}

Supplemental Figure 1: VH isotype distribution, VH family distribution and diversity

Supplemental Figure 2: gating strategy

Supplemental Table 1: Clinical and demographic data of MS patients

Supplemental Table 2: Cell counts and number of VH sequences

Supplemental Table 3: Description of sorting guidelines for the development of clonal maturation trees.

Supplemental Table 4: Lineage analysis of clonal groups between the CSF and PB.

Supplemental Table 5: Lineage analysis of clonal groups between baseline (T0) and after 6 months of treatment (T6)

\section{Figures}



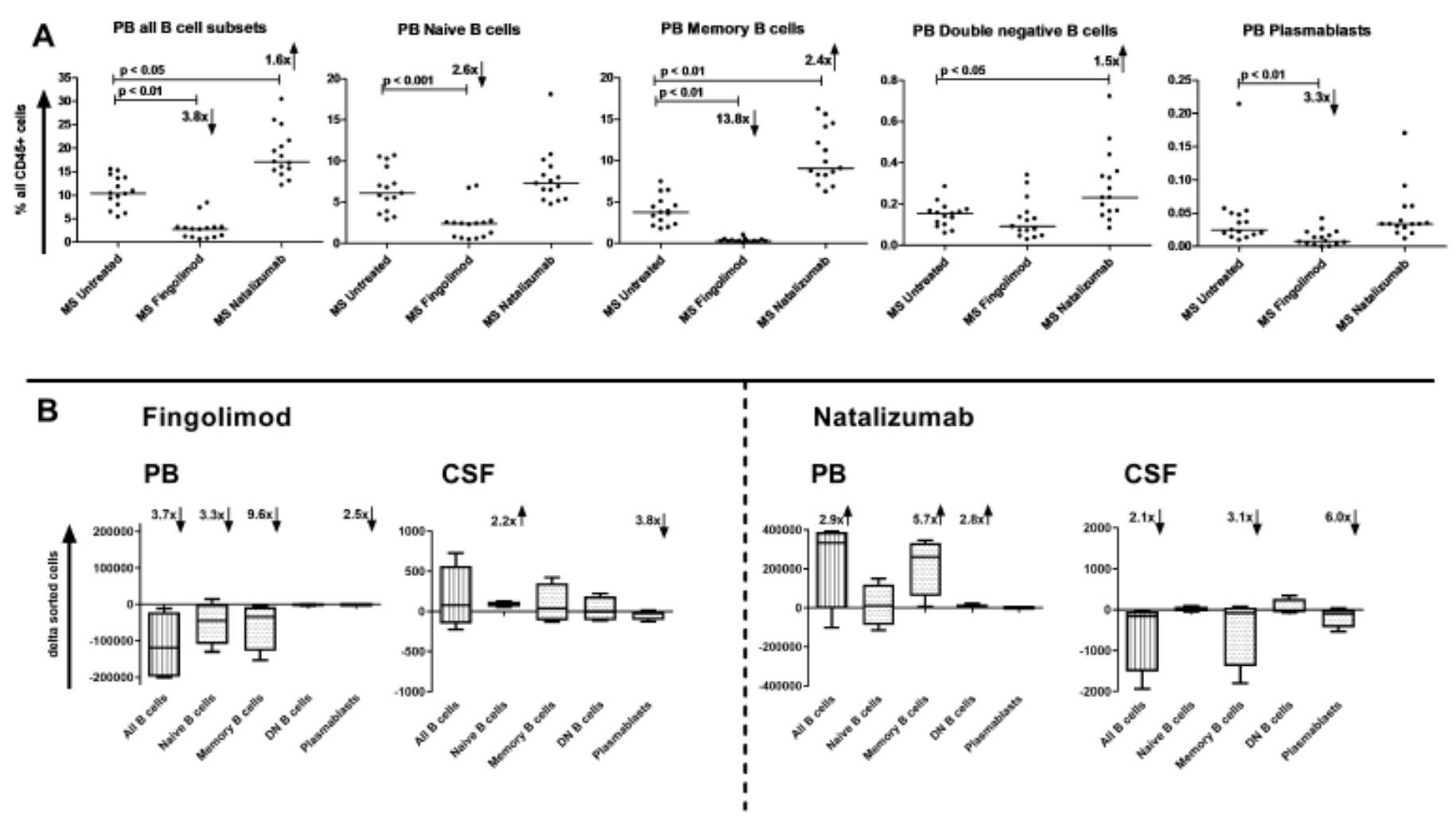

\section{Figure 1}

Distribution of peripheral blood (PB) and cerebrospinal fluid (CSF) B cell subtypes: (A) Independent analysis of peripheral blood $B$ cell subset distributions as percentage of total CD45+ cells in untreated $(n=15)$, fingolimodtreated $(n=15)$ and natalizumab-treated $(n=15)$ MS patients. The sorting paradigm for naïve, memory, double negative (DN) and plasmablast populations are defined in Materials and Methods. The number above each treatment indicates the fold change in that B cell subset relative to the untreated cohort. For statistics the Kruskal-Wallis test with Dunn's procedure was applied. (B) Changes from baseline for each PB and CSF B cell subset of patients used for repertoire analysis (fingolimod, $n=4$; natalizumab, $n=4$ ). Values are presented as the absolute difference in recovered cells from baseline for each B cell subset. Statistical significance could not be established due to limited patient numbers. 

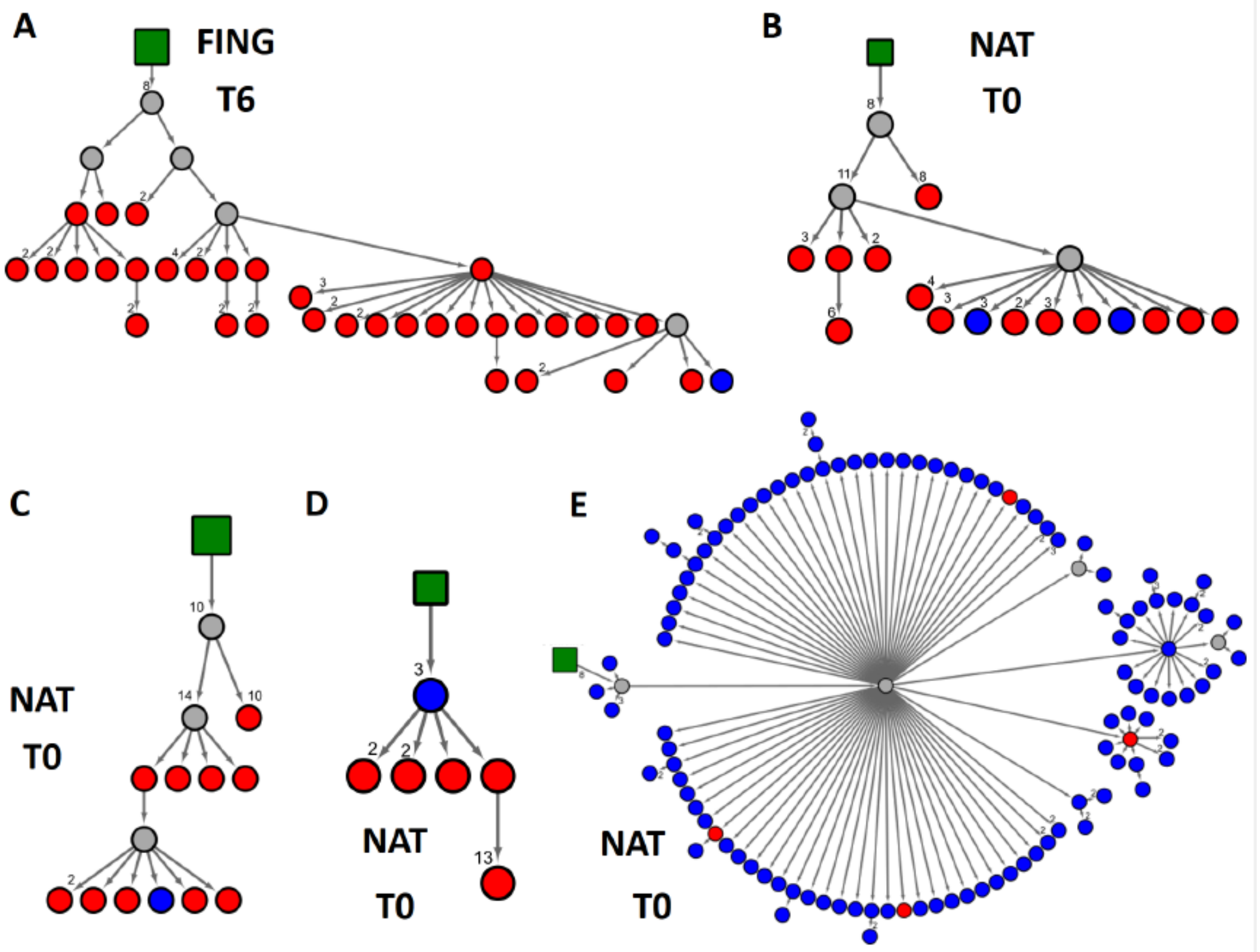

Figure 2

Lineage trees of representative clonal groups shared between the peripheral blood (PB) and cerebrospinal fluid (CSF) at baseline (T0) and following treatment (T6). Red circles represent PB B cells, blue circles CSF B cells, and grey circles indicate putative intermediates originating from the germline sequence (green square). The number adjacent to each arrow denotes the number of mutations between members of the lineage tree. The absence of a number specifies a single mutation. Maturation trees primarily expanded within the peripheral blood (PB) are shown in $A, B, C$ and $D$, whereas maturation trees that are primarily expanded within the cerebrospinal fluid (CSF) are shown in E. Direct connections between PB and CSF B cells are shown in trees A, C, D and E; whereas in tree $\mathrm{B}$, an unknown intermediate is presumed to be connecting the PB and CSF compartment. Tree $\mathrm{E}$ displays PB B cells that most likely undergo further maturation with the CSF compartment. Abbreviations: natalizumab $=$ NAT, fingolimod $=$ FING . 

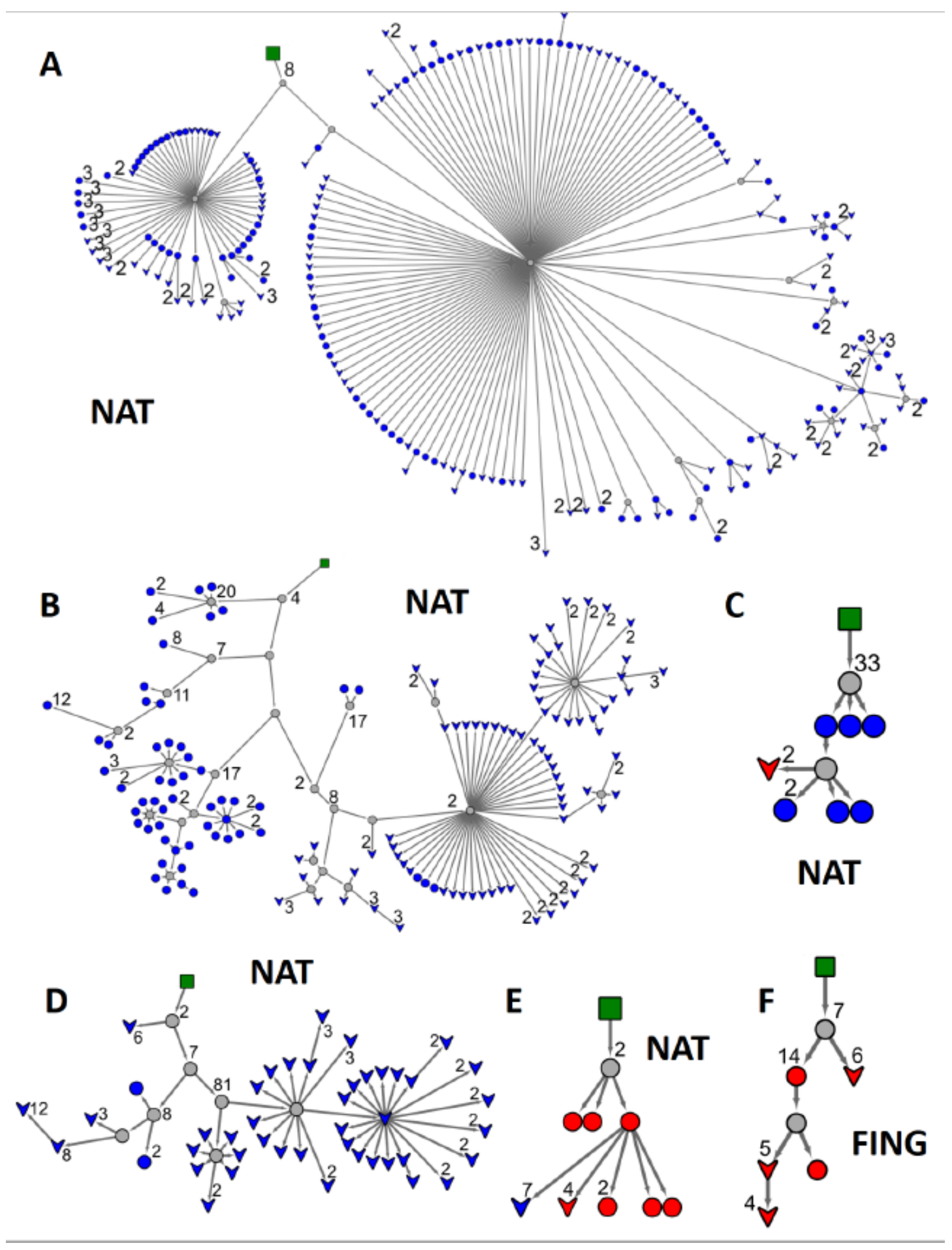

Figure 3

Lineage trees of representative clonal groups maintained in patients at baseline (T0) and following six months of treatment (T6). Peripheral blood- (red) and cerebrospinal fluid-derived (blue) B cell sequences present at baseline (circles) and 6 months (triangles) are connected by arrows tracing variable region sequence mutations from germline (green square). The number adjacent to each arrow denotes the number of mutations between members of the lineage tree. The absence of a number specifies a single mutation. (A, B, D) Large, highly branched lineage trees link the CSF compartment at baseline and 6 months following natalizumab treatment (NAT). CSF B cells at baseline connected with a high number of CSF B cells after 6 months therapy. Similar clusters were not seen following fingolimod treatment. (C) Lineage tree depicting CSF B cells connected to 
peripheral blood (PB) B cells after 6 months of NAT. (E) Lineage tree of PB B cells connected to a single CSF B cell after 6 months of NAT. (F) Lineage tree depicting PB B cells at baseline connected to PB B cells after 6 months of fingolimod treatment (FING).
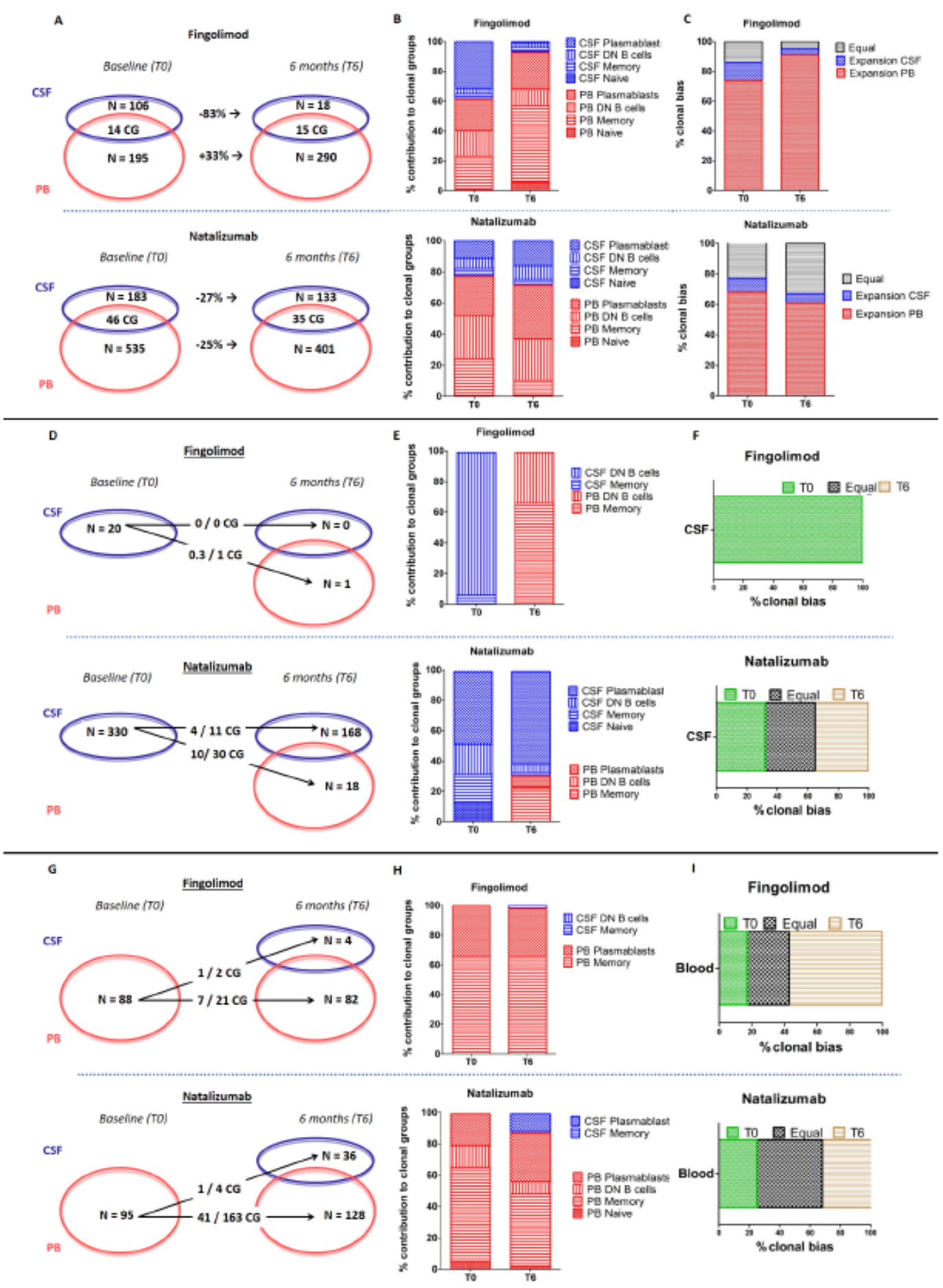

\section{Figure 4}

Lineage analysis of the clonal groups (CG) identified in both peripheral blood (PB) and cerebrospinal fluid (CSF) compartments were analyzed at baseline (T0) and after 6 months (T6) of treatment. (A) The average / total number of clonal groups and the average number of contributing sequences, (B) the composition of B cell subsets, and (C) the percentage of clonal populations dominated by PB or CSF sequences shared between the PB and CSF at T0 or T6 for fingolimod- and natalizumab-treated patients. (D) The average number / total 
number of clonal groups and the average number of contributing sequences, $(E)$ the composition of $B$ cell subsets, and $(F)$ the percentage of clonal populations dominated by PB or CSF sequences shared between the CSF compartment at TO and the CSF and PB at T6 for fingolimod- and natalizumab-treated patients. (G) The average / total number of clonal groups and the average number of contributing sequences, $(H)$ the composition of $\mathrm{B}$ cell subsets, and (I) the percentage of clonal populations dominated by PB or CSF sequences shared between the PB compartment at T0 and the CSF and PB at T6 for fingolimod- and natalizumab-treated patients.

\section{Supplementary Files}

This is a list of supplementary files associated with this preprint. Click to download.

- Kowariketal.Supplementalmaterial.pdf 